\title{
UMA CRÍTICA AO CONCEITO DE ABISMO GNOSEOLÓGICO NA TEORIA RETÓRICA DE JOÃO MAURÍCIO ADEODATO
}

\author{
A CRITIQUE TO THE CONCEPT OF GNOSEOLOGICAL ABYSS IN JOÃO MAURÍCIO \\ ADEODATO'S RHETORICAL THEORY
}

\author{
TORQUATO DA SILVA CASTRO JR. ${ }^{1}$ \\ VICTOR LACERDA ${ }^{2}$ \\ JOÃO AMADEUS ALVES DOS SANTOS 3
}

\begin{abstract}
RESUMO: A noção de abismo gnoseológico, em conjunto com a de abismo axiológico, é a base epistemológica da teoria retórica de João Maurício Adeodato. Ela faz parte dos fundamentos teóricos e apoia as teses do autor sobre a impossibilidade de comunicação plena, das verdades imutáveis e da ideia de uma etiologia jurídica. Neste artigo, buscamos demonstrar que a noção de abismo gnoseológico possui como fundamento uma teoria da linguagem como representação, e pressupõe uma ontologia calcada em teorias da mente comuns à tradição ocidental. Argumentamos, utilizando-nos de conceitos da filosofia tardia de Wittgenstein, que tais pressupostos parecem estar em desacordo com outras posições do próprio Adeodato.
\end{abstract}

PALAVRAS CHAVES: Filosofia retórica do direito. Filosofia da linguaguem. Antirepresentacionalismo. Direito e linguaguem.

ABSTRACT: The notion of gnoseological abyss, in conjunction with that of axiological abyss, forms the epistemological basis of João Maurício Adeodato's rethorical theory. It is a part of his theoretical foundations and plays a role in supporting the author's thesis about the impossibility of absolute communication, immutable truths and the idea of a legal ethology. In this article we purport to demonstrate that the notion of gnoseological abyss relies on a view of language as representation, and assumes an ontology common to the Western tradition when it comes to the theory of mind. We argue, following Wittgenstein's late philosophy, that such assumptions go against Adeodato's own positions.

KEYWORDS: Rhetorical philosophy of law. Philosophy of language. Anti-representationalism. Law and language.

1 Doutor pela PUC-SP. Professor Titular de Direito Civil pela Universidade Federal de Pernambuco. Professor permanente do Programa de Pós-graduação em Direito da UFPE (PPGD-UFPE).

2 Bacharel em Direito pela UFPE, Mestrando em Direito pelo PPGD-UFPE.

3 Bacharel em Direito pela UFPE, Mestrando em Direito pelo PPGD-UFPE. 


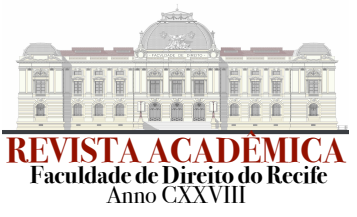

\section{INTRODUÇÃO}

A Filosofia Retórica na conformação dada por João Maurício Adeodato possui a tese, relativa ao conhecimento humano, de que a percepção dos fenômenos empíricos é construída meio a elementos irredutíveis um a outro: os eventos do mundo real (únicos e irrepetíveis), os significados (ideias da razão) e os significantes linguísticos (expressões da comunicação) (ADEODATO, 2011, p. 9). Assim, a própria realidade é linguística, o que afasta a possibilidade de acordos ontologicamente determinados sobre a constituição daquela. (ADEODATO, 2011, p. 41)

O autor, então, situa o que chama de "problema do conhecimento humano" entre duas grandes tendências: de um lado, a tradição racionalista, que remonta a Parmênides, segundo a qual o conhecimento é imanente, estando na própria natureza racional humana; de outro lado, a tradição empirista no rastro de Heráclito, que desconfia da razão como meio eleito para o conhecimento (ADEODATO, 2011, p. 31-34).

A retórica filosófica por ele defendida busca mostrar que não há um mundo exterior à linguagem, pois este é desenvolvida pelos seres humanos justamente para lidar com as diferentes apreensões do meio que realizam enquanto espécie e enquanto indivíduos (ADEODATO, 2011, p. 35-36).

Em sua obra Ética \& Retórica: Para uma teoria da dogmática jurídica, Adeodato afirma que todo teórico do direito deve se debruçar sobre dois problemas fundamentais: o de como conhecemos o mundo e o de como o avaliamos. (ADEODATO, 2000, p. 186) O primeiro problema é tratado por meio do que o autor chama de "abismo gnoseológico", enquanto o segundo é visto sob o prisma do "abismo axiológico". No presente artigo, pretendemos analisar e oferecer uma crítica apenas sobre como é posto o primeiro problema. Para tal, fornecemos ao leitor uma explicação esquemática sobre qual seria a dificuldade central da cognição humana na visão de Adeodato e o porquê deste autor afirmar que não é possível haver entendimento entre as pessoas sem mediação da linguagem. 


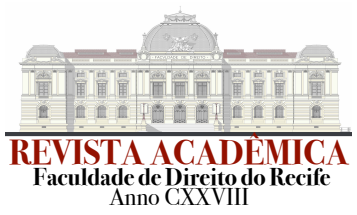

Com o intuito de caracterizar os percalços e obstáculos da cognição, o autor afirma que há uma incompatibilidade recíproca entre "as três unidades do conhecimento humano, as quais não podem ser reduzidas uma à outra". São elas: a) o evento real; b) a ideia (ou “conceito", "pensamento"); e c) a expressão linguística (ou "simbólica") (ADEODATO, 2009, p. 186). Estes três objetos fazem parte da ontologia oferecida para tratar da questão posta. Cada um deles deve ser explicado individualmente antes de serem relacionados.

\section{O ABISMO GNOSEOLÓGICO E AS INCOMPATIBILIDADES RECÍPROCAS}

\subsection{O EVENTO REAL}

Nas palavras do próprio autor, o evento real é o “o 'acontecimento' ou 'objeto' único e irrepetível que, aparentemente de maneira independente do ser humano, coloca-se presente em sua experiência e simultaneamente em sua linguagem."4 (ADEODATO, 2009, p. 186). Dentre estes "acontecimentos" e "objetos" estão itens concretos como pedras, livros, janelas, cadeiras e também os processos físicos, químicos e biológicos estudados pelas ciências naturais. Nossas experiências psíquicas internas - sentimentos, emoções - também pertencem ao mundo dos eventos. Mesmo objetos não-reais ou puramente intelectuais como os números e as formas geométricas aparecem-nos como eventos únicos e irrepetíveis quando temos um triângulo em mente. Eventos são, enfim, nas palavras do autor, as nebulosas a que o senso comum dá o nome de realidade (ADEODATO, 2011, p. 34).

Por meio desta definição temos que o evento possui como característica intrínseca a sua individualidade. Já que individuais, os eventos devem ser inteiramente irrepetíveis: é o panta rei, tudo flui, de Heráclito. Nenhum evento seria, em si, idêntico a outro evento, em respeito ao princípio da identidade que, em sua expressão mais comum, afirma que $\mathrm{A}=\mathrm{A}$ (HEIDEGGER, 1969, p. 23). Diante do que podemos chamar de particularidade radical, os

${ }^{4}$ A adição do trecho "e simultaneamente em sua linguagem" não aparece na primeira edição do Ética \& Retórica. Em que se lê apenas que o evento coloca-se presente apenas em "sua experiência" (ADEODATO, p. 288, 2002). 


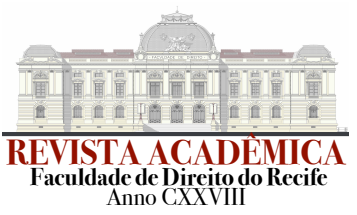

eventos ganham ares de irracionalidade (ADEODATO, 2009, p. 187), isto é, o mundo real é irracional porque jamais se repete (ADEODATO, 2011, p. 35). O sujeito cognoscente vê-se afogado em um mar de eventos dissimilares entre si, cada um com suas características particulares, diferenças de propriedades e mesmo de posição espaço-temporal ou contextual.

A situação torna-se complicada, pois nós, seres humanos, passamos a nos referir a esses eventos ou conjuntos de eventos como fatos, e a eles atribuímos valores de verdade (em geral, uma partição bivalente entre fatos verdadeiros e falsos). Também precisamos navegar nesse mar de irracionalidade, pois é a partir dele que conhecemos o mundo externo e podemos nos comunicar uns com os outros. No entanto, como seria possível fazermos tais juízos sobre objetos individuais, irrepetíveis, irracionais, infinitamente complexos e percebidos através dos sentidos? Se os eventos são infinitos e nossa capacidade sensorial é finita, precisaríamos reduzir este excesso de complexidade antes de podermos falar ou mesmo apreender os eventos. É preciso agrupá-los. Entra o segundo objeto do conhecimento humano, a ideia.

\subsection{A IDEIA}

Se os eventos são únicos e irrepetíveis, as ideias, por outro lado, são necessariamente gerais. Esta característica representaria uma incompatibilidade entre a mente humana, "que só constrói generalidades", e o mundo dos eventos que é "irracional porque jamais se repete". Para fazer jus a esse dualismo evento/ideia, Adeodato assim define esta última: "Por idéia compreende-se o estímulo que se completa no sujeito no ambiente de seu defrontar-se com os eventos, pois o ser humano é experiência, existe no mundo real.” (ADEODATO, 2009, p. 188).

O sujeito imerso no mundo dos eventos só pode começar a compreendê-lo por meio deste processo de abstração, em que o sujeito cognoscente obtém uma ideia (ou conceito, juízo - usados como sinônimos) a partir de uma seleção de aspectos particulares dos eventos. Isto é, se os eventos aparecem, enquanto tais, envoltos em uma infinidade de traços, é preciso que alguns desses traços sejam deixados de lado e que outros sejam priorizados e 


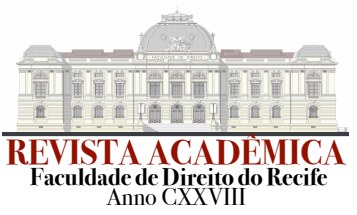

transformados em uma ideia, que é única e geral. Esta seleção é altamente individual e, sugere Adeodato, diferente para todos os indivíduos.

Para tornar a explicação mais compreensível, podemos oferecer um exemplo. O indivíduo formaria a ideia de "telefone celular" ao ser exposto a um grande número de objetos suficientemente similares entre si (ainda que ontologicamente diversos, dado que se tratam de eventos únicos). Manipularia esses objetos, constataria que eles possuem um display, tela sensível ao toque, formato comumente retangular; ao mexer com o aparelho perceberia que alguns possuem funções de câmera fotográfica, que servem para fazer ligações a outros telefones, mandar mensagens instantâneas etc. A partir dessa exposição a tais itens, o indivíduo tentaria identificar o que há de comum entre todos eles e a ideia seria um produto desse processo. Com a ideia de celular em mãos (ou na cabeça) o indivíduo estaria apto a falar sobre telefones celulares com outros seres humanos, imaginar telefones celulares na própria consciência e até mesmo reconhecer, classificar e nomear objetos nunca antes vistos por ele como sendo, ou não, telefones celulares.

Deve haver, portanto, conceitos que exprimam certos objetos de forma geral. Temos uma ideia de caneta, outra de livro, outra de par de óculos e assim por diante. Ideias devem corresponder ao mesmo modo a propriedades físico-químicas como dureza, resistência, condutividade, inflamabilidade, peso, massa, gravidade, etc. Nem mesmo a matemática fica de fora: os números; os operadores da aritmética; os conectivos da lógica formal; os conceitos de ponto, reta e plano da geometria euclidiana; a todos eles correspondem ideias. Se tomarmos também discursos de natureza psíquica, podemos falar até mesmo de uma ideia de "estar sentado em frente a um computador digitando palavras por meio de um teclado com o intuito de escrever um artigo científico e submetê-lo a uma revista acadêmica".

Um ponto deve ser ressaltado. Apesar de a ideia ser geral, as nossas percepções das ideias são também parte do plano dos eventos e, portanto, individuais, únicas aos sujeitos que as produzem. Há uma incomunicabilidade entre a ideia e a sua percepção, bem como entre a ideia e a expressão simbólica (ou linguística), terceiro objeto do conhecimento humano (ADEODATO, 2007, p. 190). 


\subsection{A EXPRESSÃO SIMBÓLICA}

Por fim, a expressão simbólica implica o retorno das ideias à realidade, tudo por meio da linguagem. Ao buscar se comunicar, o indivíduo quer representar as suas ideias mas só pode fazê-lo de maneira incompleta e insatisfatoriamente generalizada (ADEODATO, 2007, p. 191). A representação nunca é um para um, há sempre aspectos ocultos e incomunicáveis.

A problemática da expressão simbólica é de especial interesse para o direito, área de conhecimento expressa fortemente em regras escritas (ou faladas) em linguagem natural. A impossibilidade de correspondência perfeita entre as ideias humanas e suas consequentes expressões explicaria o porquê de haver discordância quanto às diversas interpretações de um mesmo texto legislativo, de um contrato ou qualquer outro instrumento jurídico escrito ou oral. A adequação entre normas e condutas também se complica, já que os profissionais do direito estarão sempre em desacordo sobre pontos específicos das mais diversas categorias jurídicas.

Como a expressão simbólica ocorre espaço-temporalmente ela é, em si mesma, mais um evento, o que reinicia o ciclo do conhecimento: o sujeito se depara com eventos, forma ideias e as comunica. No entanto, como a ideia, ela possui um significado que é geral. Entenderemos isso melhor mais adiante.

\subsection{AS RELAÇÕES ENTRE AS TRÊS UNIDADES DO CONHECIMENTO HUMANO}

A figura a seguir dá uma imagem esquemática de todos os passos dados pelo conhecimento humano na concepção de Adeodato: 


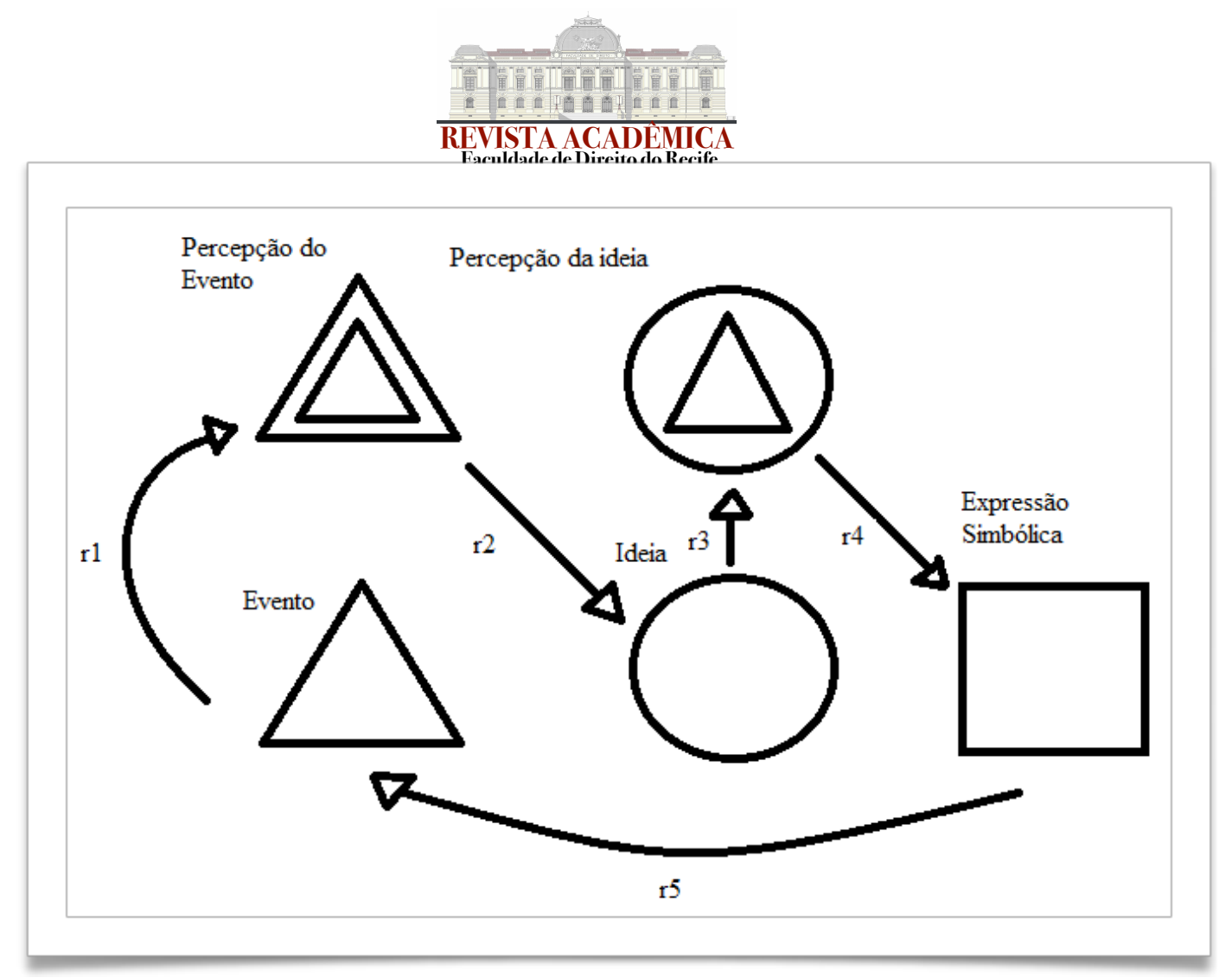

Figura 01

O triângulo representa os eventos, o círculo representa as ideias e o quadrado, a expressão simbólica. A relação "r1" descreve o contato sensorial do homem com os eventos, que se fazem entender pela mente humana através do processo de abstração (a relação "r2") e consequente construção de uma ideia. "A idéia é o resultado de um processo que tenta abstrair os aspectos particulares dos eventos e detectar neles algo de comum, que permita reuni-los em “classes", em "setores" ou coisa que o valha, em suma, classificá-los." (ADEODATO, 2009, p. 188) Em seguida, o homem percebe a ideia (relação "r3") e a externaliza através da expressão simbólica que, por sua vez, é também um evento e assim por diante. Optamos por não representar a expressão simbólica como um quadrado com um triângulo interno pois Adeodato afirma que há uma diferença fundamental entre ela e os eventos, ainda que aquela torne-se parte deste durante a comunicação. (ADEODATO, 2011, p. 38). É que a expressão simbólica é sempre geral, enquanto o evento é individual. Separa-se o significante entre aquilo que ele expressa e o signo por meio do qual ele faz tal expressão.

O abismo, então, se dá na impossibilidade de eu perceber as representações que os outros humanos fazem. As classificações dos indivíduos não são unívocas, têm peculiaridades e maneirismos únicos e idiossincráticos que se perdem tanto quando agrupamos os eventos e os transformamos em ideias, quanto quando tentamos falar sobre essas ideias por meio de 


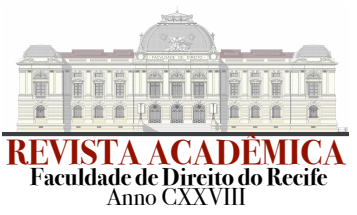

significados gerais e abstratos. A única possibilidade de verdade, então, torna-se o consenso. E os seres humanos agem retoricamente quando pretendem falar de verdade e de fatos. A realidade, então, é uma construção feita pelo "relato vencedor", mediante sua força persuasiva ("quem" diz, "o que" é dito e "como" é dito, ou seja, o ethos, o logos e o pathos do discurso) (ADEODATO, 2009, p. 53).

O relato vencedor constrói o que se tem por realidade, designada pela retórica filosófica pelo conceito de "retórica material", a qual é composta por esses consensos mutáveis, relatos vencedores estes sempre temporários que podem ser derrubados ou mantidos a depender do discurso dos indivíduos. O senso comum teria na retórica material a sua "realidade". A retórica estratégica, situada em um nível mais alto, estudaria os meios mais efetivos de se interferir sobre essa retórica material. Os tópicos de Viehweg e muitas das heurísticas e técnicas da dogmática jurídica se encaixam nesse nível da análise. Por último viria a retórica analítica, como uma tentativa de afastar o sujeito desse oceano de mutabilidade e tentar ser o mais descritivo possível sobre os consensos e realidades que o cercam.

\section{A PREMisSa OCULTA QUANTO AO FUNCIONAMENTO DA EXPRESSÃo SIMBÓLICA}

\subsection{A RETÓRICA MATERIAL, O RELATO VENCEDOR E A FUNÇÃo REPRESENTATIVA DA EXPRESSÃO SIMBÓLICA}

Defende-se neste artigo haver uma premissa oculta no argumento de Adeodato: a de que a linguagem serve, essencialmente, para fazer representações. A ideia seria incapaz de representar os eventos e a expressão simbólica - a linguagem - seria incapaz de representar as ideias com perfeição. Aí está descrita a dupla falha da compreensão a que somos apresentados, indicada na Figura I pelas relações "r2" e "r5". Ao afirmar que há uma inadequação entre ideias e expressões gerais para se referir a eventos individuais e que isto seria uma "enfermidade do discurso" (ADEODATO, 2009, p. 192) pressupõe-se que a 


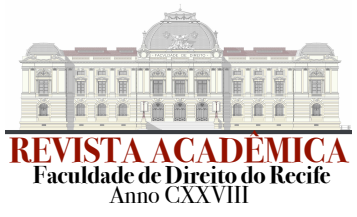

representação é a finalidade derradeira da linguagem. O ponto interessante, aqui, está no fato de que as teorias que concebem a linguagem como representação da realidade estão mais aproximadas à tradição racionalista, no rastro de Parmênides, Platão e Descartes, tradição esta, que, como visto, é rechaçada pela retórica filosófica de Adeodato em favor da tradição filosófica empirista que remonta a Heráclito.

Para usar uma metáfora cara aos juristas, poderíamos falar antes não de um abismo gnoseológico e sim de uma lacuna gnoseológica. Na teoria de Adeodato, a lacuna é preenchida (outra metáfora familiar aos filósofos do direito) por consensos instáveis da linguagem, o que deságua na conclusão de que a realidade é composta apenas pela retórica material. Mesmo não havendo correspondência exata sobre ideias percebidas e expressões os seres humanos precisam se fazer compreender de algum modo: o engenheiro precisa fazer cálculos e comunicá-los aos trabalhadores, a juíza precisa emitir um comando e o jurisdicionado precisa segui-lo, o jovem estudante precisa avaliar se uma certa assertiva sobre história é verdadeira ou falsa. Em todas essas situações haveria uma concordância linguística contingente e passível de mudança, sem que pudéssemos recorrer a um critério objetivo e externo à linguagem para decidir sua correção. Não haveria uma etiologia da realidade, nem mesmo redes causais complexas às quais se atribuir uma "causa" passada, pois o que é real apenas o seria de modo contingente e construído momento a momento (ADEODATO, 2011, p. 131).

Aqui sequer negamos a existência de lacuna. Afirmamos que insistir em metáforas explicativas que se valem de conceitos afins como "encaixe", "correspondência", "representação", “adequação", “comunicação plena” é como tentar acelerar um carro em ponto morto e quedar-se perplexo quando ele não sair do lugar. Nesta seção, apontamos que conceber a linguagem meramente como um sistema de representação priva-lhe de seus aspectos mais complexos e interessantes, e que o trinômio evento-ideia-expressão pode no máximo prover uma imagem sedutora do que entendemos como o processo de 'nomear' e, talvez, de como tratamos o jogo de linguagem a que pertencem as proposições, mas nunca da totalidade da linguagem e suas diversas funções. 


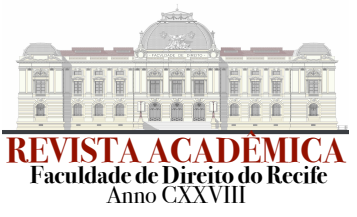

O argumento que se segue terá como fio condutor a segunda filosofia da linguagem de Wittgenstein, principalmente tomando-se como base as Investigações Filosóficas (IF) e o Sobre a Certeza (SC), mas também alguns da fase intermediária dos anos 30: Observações Filosóficas (OF), Gramática Filosófica (GF) e os Livros Azul e Marrom (AM). Onde for necessário, utilizaremos também o Tractatus Logico-Philosophicus (TLP) a título de comparação.

Antes de procedermos, um aviso. Neste artigo adotamos o método usual de citação aos trabalhos de Wittgenstein. Como todas as edições de seus livros possuem as sessões escritas uniformemente enumeradas, apontamos o trabalho a que nos referimos por meio de siglas seguidas pela sessão em questão. As edições consultadas especificamente constam nas referências.

\subsection{DESIGNAR, NOMEAR E EXPRIMIR}

"Todo signo, sozinho, parece morto. O que lhe confere vida? - Ele está vivo no uso. Ele tem em si o hálito da vida? - Ou é o uso o seu hálito?"

(IF, 432)

Recusamos, de início, a concepção de linguagem como representação e adotamos a perspectiva de significado como uso (IF, 43). Nos parágrafos seguintes expõe-se o porquê dessa opção e como ela parece, inclusive, ser mais adequada como base a uma teoria retórica do direito.

$\mathrm{Na}$ abertura das Investigações Filosóficas, Wittgenstein chama a atenção para uma passagem das Confissões de Santo Agostinho, em que o filósofo medieval discutia o aprendizado da linguagem, relacionando-o com o ato de apontar-se a um objeto e de nomeálo:

\footnotetext{
"Quando os adultos nomeavam um objeto qualquer voltando-se para ele, eu o percebia e compreendia que o objeto era designado pelos sons que proferiam, uma vez que queriam chamar a atenção para ele. [...] Assim, pouco a pouco eu aprendia a compreender o que designam as palavras que eu sempre de novo ouvia proferir nos seus devidos lugares, em diferentes sentenças. Por meio delas eu expressava os meus desejos, assim que minha boca se habituara a esses signos.” (IF, §1)
} 


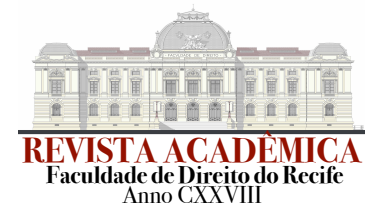

Esta imagem, para Wittgenstein, seria uma explicação perfeita do que a tradição filosófica ocidental entende por significado: as "palavras da linguagem designam objetos", do concluindo-se que "toda palavra tem um significado". (IF, §1) Ela representaria o tipo de intuição pré-teórica que tem servido de base às diversas teorias do significado e do conhecimento da filosofia continental e analítica em geral. Wittgenstein não nega que este tipo de comportamento ocorra, sequer declara que ele é inútil. (IF, §6) Observa, no entanto, que ele não nos diz de fato como nos comunicamos em todos os casos. Por intermédio do comportamento narrado por Santo Agostinho, há apenas um ensino ostensivo das palavras, um domínio extremamente circunscrito do que entendemos por significado. A descrição de Agostinho nos dá o entendimento de um sistema de comunicação, só que nem tudo o que chamamos de linguagem é esse sistema (IF, §3). Por meio desse tipo de ensino o indivíduo estabelece uma ligação associativa entre a palavra e a coisa; mas, pergunta Wittgenstein: é esta a finalidade da palavra? (IF, §6)

Deste modo, vimos que aquilo que Adeodato explica com seu abismo é o jogo de linguagem de nomear e classificar eventos. No entanto, trata-se de um espaço extremamente circunscrito do que fazemos com a linguagem. Aprendemos a observar eventos e a classificálos, mas, o que vem depois? O que posso fazer com este conceito além de proferir seu nome? Em quais atividades posso empregá-lo e como ele deve ser entendido pelos outros? Para usar o título do livro de J. L. Austin: como fazer coisas com palavras? Ter uma ideia, um conceito, e representá-lo através de uma expressão simbólica (iremos mais na frente também atacar este objeto) pode ser entendido como uma preparação para o seu uso.

Sobre este último ponto, o da preparação, podemos pensar no exemplo do xadrez dado por Wittgenstein. Caso dispusermos as peças do jogo enfileiradas, pegarmos a que corresponde ao rei e dissermos "Este é o rei no xadrez", ainda não explicamos nada a alguém que não saiba as regras do xadrez de antemão. (IF, §31). O aprendiz "terá em mente" a forma da figura do xadrez e poderá nomeá-la dentre as outras peças, mas não saberia quais tipos de movimento seriam conformes, que matar o rei é o objetivo do jogo, que com ele pode-se fazer um roque, etc. Para aprender o papel de qualquer peça do xadrez, é preciso aprender antes uma atividade. Para entender o que é uma peça, é preciso saber que papel ela desempenha em 


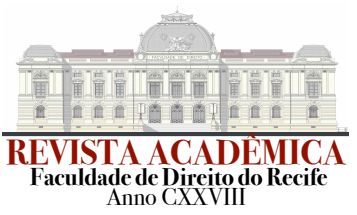

um jogo. É neste sentido que Wittgenstein vai dizer que acionar o freio unindo a barra com a alavanca só ocorre quando supomos o resto do mecanismo. Só em relação ao mecanismo é a alavanca um freio (IF, §6).

Talvez o que seja mais surpreendente na trindade gnoseológica de Adeodato é a admissão, mais ou menos implícita, de que se pode significar em isolamento:

"A condição humana, porém, faz com que esses eventos só possam ser compreendidos pela razão humana em termos genéricos, sem correspondência precisa com os eventos. Para isso, seleciona frações do evento em detrimento de outros atributos que são ignorados ou sequer percebidos. Ao conjunto dessas frações intuitivamente, instintivamente selecionadas, corresponde uma ideia, uma unidade de razão. A essa ideia o ser humano atribui um nome ou conjunto de nomes e a corporifica em um condutor físico (significante), criando a comunicação." (ADEODATO, 2011, p. 135)

A apreensão da ideia parece ocorrer aqui num vácuo linguístico, apartada das atividades desenvolvidas no seio da linguagem. Atribuir nomes e os corporificar torna-se a preocupação central da comunicação, vista aqui quase como uma troca de figurinhas ideais por meio de sinais físicos e presentes no espaço-tempo. Não é de se surpreender que, quando postulamos tais restrições metafísicas, a comunicação começa a parecer um evento estranho e falho, permeado por pequenas imperfeições.

Wittgenstein argumenta contra tal concepção ao afirmar que Santo Agostinho (e a tradição que equaciona significado e representação) "descreve a aprendizagem da linguagem humana como uma criança que chegasse a um país estranheiro e não entendesse a língua do país; isto é: como se ela já tivesse uma língua, só que não esta.” (IF, §32). Para a concepção tradicional, como bem explica Helena Martins, o aprendizado de uma língua pública passa a pressupor a posse prévia de uma espécie de linguagem interior, uma linguagem do pensamento (MARTINS, 2000, p. 25).

Em nosso caso, essa língua anterior a do indivíduo em seu íntimo é populada pelas ideias. Como as ideias são gerais e a percepção das ideias pelos indivíduos é única e irrepetível, não há correspondência de um para um entre a ideia e a sua percepção. Adeodato, então, conclui pelo caráter retórico até mesmo do diálogo entre o indivíduo consigo próprio. 


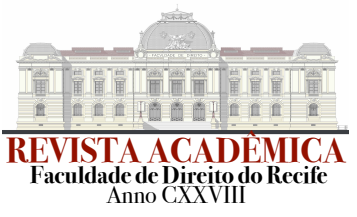

Dentro desta perspectiva, é natural que o texto normativo apareça como um significante e provoque a necessidade de interpretação (ADEODATO, 2011, p. 137). O texto seria o portador, carregaria consigo o significado como a pérola em uma concha, a ser decodificado por outro destinatário; visão negada por Wittgenstein (CASTRO Jr., 2011, p. 1081). A trindade gnoseológica tenta combater os diversos ontologismos, contudo opera dentro de suas amarras metodológicas. A diferença está apenas no ceticismo particular da retórica filosífica de Adeodato, rejeitando a possibilidade de entendimento ontológico e não retórico: o significado geral expresso pelo significante jamais pode ser entendido plenamente pelo destinatário.

O alcance dessa intuição da linguagem como representação se faz presente na teoria da norma do autor, quando ele sugere que entendamos os significados (as normas) como "promessas ideais dirigidas ao futuro e que os significantes são tentativas de acordos fixados no passado e agora chamados diante de um caso atual, presente." (ADEODATO, 2011, p. 156). Tal definição sugerida vai na mesma linha de Hart, para quem a norma funcionaria como um guia para condutas futuras. (BIX, 1993, p. 2). É dentro de uma reflexão que parte de tais premissas e vê a norma nestes termos que o próprio Hart conclui que há casos fáceis e casos difíceis, que estes últimos se encontram em uma zona de penumbra e que neles há a presença do poder discricionário do juiz em criar direito (HART, 2012, p. 135). Em ambos os casos o pensamento referencialista parece estar presente.

Apesar de nunca ter lidado diretamente com o direito, nem com normas jurídicas em sentido estrito, Wittgenstein dedicou boa parte de seus esforços intelectuais sobre a questão de seguir-uma-regra ${ }^{5}$, um conceito que guarda grande afinidade com as discussões jurídicas sobre estar ou não estar de acordo com uma norma. Ele nos pergunta: "Donde vem a idéia de que a série iniciada seria um trecho visível de um trilho que se estende invisivelmente até o infinito? Ao invés de regra, poderíamos imaginar trilhos” (IF, §218). Enquanto Adeodato, e provavelmente também Hart, rejeitariam a imagem caso disséssemos que os trilhos estão fixos, poderiam talvez continuar a metáfora dizendo que o trilho é construído à medida que é

\footnotetext{
5 Regra, aqui, não deve ser entendida nos termos postos pela filosofia do direito em que uma regra se opõe a um princípio.
} 


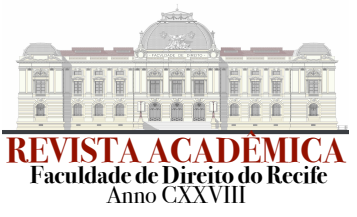

usado. Já se escreveu bastante entre a relação entre o conceito de seguir-uma-regra em Wittgenstein e as normas jurídicas, inclusive sobre a seção 218.

\section{A EXPRESSÃO SIMBÓLICA É, DE FATO, GERAL?}

Uma das insistências mais categóricas de Adeodato é a de que qualquer texto entendido em sentido lato, pode incluir tanto este artigo, quanto um discurso, um quadro pintado a óleo, leis, notas musicais, pedras esculpidas pertence tanto ao mundo dos eventos quanto da expressão linguística.

Isto implica que algo pode ser um evento e não ser uma expressão linguística e que toda expressão linguística é acompanhada de um evento, ainda que sejam noções distintas. Se por um lado o objeto textual em si é um evento (um livro existe no espaço-tempo, pode ser tocado, analisado segundo os sentidos), a comunicação feita por intermédio do texto provoca uma "compreensão de caráter ideal que não se confunde com os eventos-objetos". (ADEODATO, 2011, p. 135)

É por isto que na Figura 1 fomos obrigados a representar a expressão simbólica como um quadrado e não como um quadrado preenchido por um triângulo. O retorno ao mundo dos eventos se daria por meio da relação "r5", não através da expressão simbólica em si, já que esta seria geral e ideal. Um outro modo de apresentar a questão é através da utilização dos conceitos de significante e significado. Enquanto o significante (a base concreta do texto) é individual, o significado (aquilo a que o significante se refere) é geral e ideal.

O que buscamos apontar é que a divisão entre um significado ideal e sua expressão objetivada através de um objeto ou ato físico não são distintas como se pretende. 


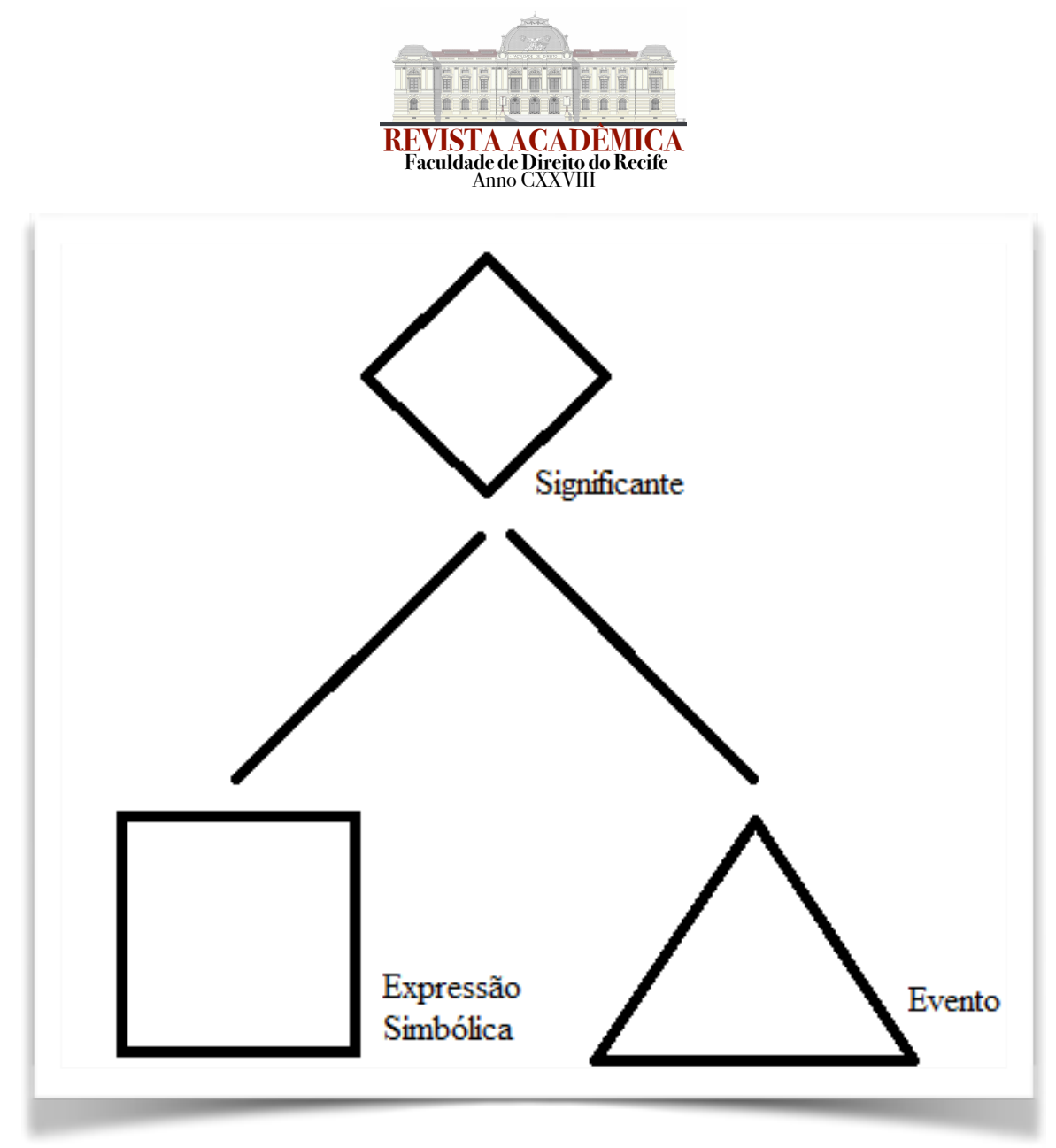

Figura 02

O esquema da Figura 2 mostra bem a separação pretendida quanto ao significado das palavras. Enquanto o ato e objeto físico da comunicação são eventos (e, portanto, únicos e irrepetíveis), a expressão simbólica (o significado) é geral e ideal. Este último ponto, em relação ao significado ser geral, é bastante importante. Adeodato defende que é um absurdo que a expressão simbólica seja individual e, se ela assim fosse, ela poderia ser reduzida a um evento. Ela não pode pois nem mesmo nomes próprios, nem indicadores (isto, isso, aquilo, aqui, hoje etc.) mencionam algo individual (ADEODATO, 2011, p. 139).

Apliquemos o esquema de Adeodato a um caso limite: a de um ser humano nascido e criado em uma ilha, que passou a viver sozinho por um motivo qualquer. Durante a sua vida este indivíduo entraria em contato com o mundo exterior: com coqueiros, água salgada, água doce, peixes, pedras, areia, folhas, árvores, gramíneas, insetos dos mais diversos tipos, etc. Talvez não fosse capaz de nomeá-los como nós, mas seria obrigado a experimentar tais eventos individuais por meio dos sentidos e a formular uma ideia geral sobre o que eles são. Além disso, precisaria necessariamente desenvolver técnicas rudimentares que garantissem 


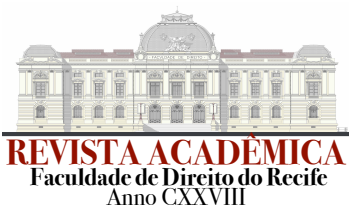

sua sobrevivência. Digamos, então, que um dos meios que este homem encontrou para permanecer vivo foi a pesca. Em suas andanças ele descobriu uma caverna subterrânea e percebeu que caso ele deposite peixes em seu interior eles se estragam mais vagarosamente do que o normal. Ele não sabe explicar o porquê de isso acontecer - talvez a temperatura lá seja um pouco mais baixa do que a beira-mar, talvez seja a falta de contato com a luz do sol; pouco importa.

Como a caverna ficava longe da praia, ele desenvolveu um sistema para se lembrar com precisão de quantos peixes estão guardados em sua caverna: para cada peixe lá depositado ele adiciona uma concha a uma pulseira rudimentar; e para cada peixe retirado da caverna, ele também retira uma concha desta pulseira. Agora vem o acontecimento importante. Certa vez, ao despertar, ele tenta decidir se precisa pescar ou não naquele dia e, para tanto, olha para a sua pulseira e vê uma única concha ${ }^{6}$. Ao colocar os olhos sobre a concha, vem-lhe na cabeça a imagem de um peixe na caverna e, baseado nisto, ele decide que precisa reabastecer o seu estoque e se lança à pesca. Passados diversos meses, talvez até anos, o pescador é surpreendido pela chegada de outro indivíduo na ilha. O novato parece ter chegado com o auxílio de uma jangada e está muito abatido. É muito jovem e logo se submete às ordens do pescador original. Este, desconfiado com o estranho, não o mostra a caverna onde guarda sua principal fonte de alimentos. Passa, todavia, a utilizá-lo como seu ajudante: toda as vezes que o estoque de peixes chega a um, ele levanta o braço, deixando à mostra a concha presa à sua pulseira e aponta para ela. Ao ver este sinal, o novato põe-se a pescar enquanto o outro guarda e pega os peixes em segredo na caverna.

Agora, perguntamos: como devemos entender o papel da concha para estes dois homens?

Pode-se dizer que ela é, definitivamente, um signo? Nem mesmo isto. No esquema de Adeodato, o primeiro homem necessariamente tem uma ideia de o que são peixes e conchas (abstraiu as características individuais de cada peixe e de cada concha) e, pela recorrência à concha, representou o peixe, realizando uma comunicação a si próprio. Isto quer dizer que a

\footnotetext{
6 É importante assinalar que o homem não tem necessariamente uma intuição matemática, isto é, ainda não concebeu os números, nem as operações da aritmética, ainda que tenha alguma noção primitiva de unidade e correspondência.
} 


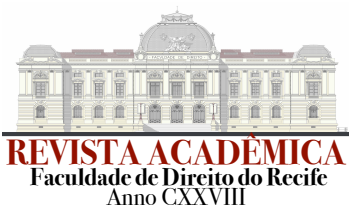

concha deixa de ser uma mera concha e passa a significar a ideia de que há um peixe na caverna, ela carrega consigo um conteúdo bastante específico, dotado de uma intencionalidade totalmente inexistente no caso de alguém para alguém que nunca fez a associação entre conchas e peixes. Posto desse jeito, haveria sentido de falar da conchaenquanto-signo para o homem mais velho.

O outro homem, contudo, pode sequer considerar a concha como o substrato da ordem. Talvez ele veja o conjunto dedo-pulseira-concha como o signo, e não a concha em sua individualidade. Isto acontece, por exemplo, quando aprendemos uma língua estrangeira e pronunciamos duas palavras como se fossem uma só ou o contrário. (Pense em expressões como meanwhile ou every time do inglês ou aujourd'hui do francês) Mesmo que disséssemos que ambos percebem a concha como um signo, o segundo homem não tem em mente peixe em caverna alguma: ele sequer sabe da existência desse esconderijo. E ainda assim põe-se a pescar ao vê-la e, ao proceder deste modo, está sempre em acordo com o pescador original.

O que propomos aqui é: o que importa para que a concha seja entendida como linguagem não é a ideia que se faz dela, mas sim o seu uso em um jogo de linguagem específico. Para fazer referência à epígrafe desta seção, a concha ganha vida não por meio de uma ideia abstrata de concha, e sim por desempenhar um papel fundamental nos jogos de linguagem dos homens. Não haveria, no exemplo, necessidade de recorrer a qualquer tipo de entidade mental imagética para explicar o seu funcionamento.

Para o pescador original, a concha faz parte de dois jogos distintos: o de "representar" o peixe na caverna e o de assinalar a necessidade de se buscar mais deles. Para seu subordinado, a concha aparece unicamente como uma ordem ou sugestão. Poderíamos imaginar, é claro, que esse desentendimento pudesse gerar problemas para os dois mais à frente. Se o pescador novato ganhasse a confiança do mais velho e este o mostrasse a caverna e lhe explicasse que uma concha corresponde a um peixe, haveria uma mudança de significado porque haveria uma mudança do uso que se faz da concha: "When languagegames change, then there is a change in concepts, and with the concepts the meanings of words change" (SC, §65). 


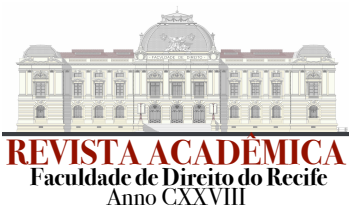

O exemplo acima é apenas uma versão alterada do jogo de linguagem descrito no $§ 2$ das Investigações Filosóficas:

"Imaginemos uma linguagem para a qual a descrição dada por Santo Agostinho esteja correta: a linguagem deve servir ao entendimento de um construtor A com um ajudante B. A constrói um edifício usando pedras de construção. Há bloco, colunas, lajes e vigias. B tem que lhe passar as pedras na seqüência em que A delas precisa. Para tal objetivo, eles se utilizam de uma linguagem constituída das palavras: "bloco", "coluna", "laje", "viga". A grita as palavras: - B traz a pedra que aprendeu a trazer ao ouvir esse grito. Conceba isto como uma linguagem primitiva completa." (IF, §2)

A insistência de Adeodato em separar um substrato fático e um substrato geral no significante é uma decorrência das restrições metafísicas do trinômio gnoseológico. Apesar de não utilizar esse conceito diretamente, depreende-se que o que anima o signo morto é a intencionalidade da consciência humana, o fato de ele exprimir uma ideia. Isto fica bastante claro quando Adeodato afirma que "o significante cristaliza significados, é como que um portador deles, provoca a necessidade de interpretação do signo". (ADEODATO, 2011, p. 137). No exemplo dado, um tal esquema parece adquirir ares de artificialidade. Não há propriamente nenhuma ideia "geral" atrás da concha, há apenas ela, o signo, e a função por ela desempenhada nos jogos de linguagem dos dois homens.

Não devemos cair no erro, por mais tentador que seja, de afirmarmos que os homens não estão de fato se entendendo, ou que não sabem realmente (quando filosofamos palavras como essas em itálico tornam-se perigosas) o que querem dizer com a concha. Tudo o que há para eles é o seu comportamento diante do signo, que pode ser emendado e modificado caso precisam usá-lo para outros propósitos.

Essa imagem de que um significante é a expressão de uma ideia parece fixar-se em nossas mentes de maneira indelével, principalmente quando pensamos em objetos concretos, nos grandes substantivos da linguagem. O próprio Adeodato usa como exemplos de eventos transformado em ideias objetos como: cadeira, ventilador, caneta. Nossa tendência a ver o substantivo e buscar o que ele representa é a causa dos muitos "o que é o que és" da filosofia: o que é "justiça"?; o que é "direito"?; o que é "moral"?; o que é a "norma"? Wittgenstein faz uma advertência sobre este tipo de enfoque: "Uma causa principal das doenças filosóficas dieta unilateral: alimentamos nosso pensar com uma só espécie de exemplos” (IF, §593). 


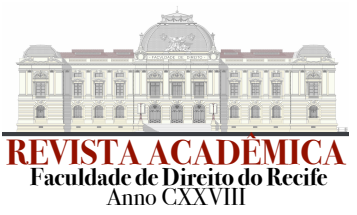

Aqui não serve de contra-argumento o fato de Adeodato negar a possibilidade de uma investigação ontológica fora da linguagem sobre os conceitos de justiça, moral, etc. Essa impossibilidade decorre do abismo, da falta de representação precisa. Em Wittgenstein não há nada para o qual o nome serve como um portador, significado não é uma relação entre consciência e palavra. É aprendido dentro de uma forma de vida (Lebensform), a partir de alguns jogos de linguagem extremamente simples que podem se tornar mais complexos ao longo do tempo.

Para piorar a situação, dentro do esquema dos três objetos fundamentais do conhecimento, a noção de ideia acaba por indicar um regresso ao infinito já que a percepção da ideia é ela também um evento. De modo que ele pode continuar a formular novas ideias a partir das suas percepções de ideias. Colocado de outro modo: se ele tem uma ideia ' $\mathrm{x}$ ' e percepções $\left(\mathrm{x}_{1}, \mathrm{x}_{2}, \mathrm{x}_{3}, \mathrm{x}_{4} \ldots \mathrm{x}_{\mathrm{n}}\right)$, ele pode formar uma ideia ' $\mathrm{y}$ ' baseada apenas nessas percepções $\left(\mathrm{x}_{1}, \mathrm{x}_{2}, \mathrm{x}_{3}, \mathrm{x}_{4} \ldots \mathrm{x}_{\mathrm{n}}\right)$ e, do mesmo modo, ideias $\left(\mathrm{y}_{1}, \mathrm{y}_{2}, \mathrm{y}_{3}, \mathrm{y}_{4} \ldots \mathrm{y}_{\mathrm{n}}\right)$, sobre as quais ela pode formular uma ideia ' $z$ ' e assim por diante. Diante deste regresso, podemos mesmo afirmar que a ideia é uma "unidade geral"? Como seria sequer possível sequer falar em representação de uma entidade tão instável?

A noção de evento é também bastante problemática. Apesar de afirmar que sua teoria retórica tem como intuito o de demonstrar que não há um mundo exterior independente da linguagem (ADEODATO, 2011, p. 36), os eventos são claramente objetos que pertencem à esfera do que existe, isto é, a uma ontologia. Afirmar que existe um evento a ser captado por um $\mathrm{Eu}$ consciente é o mesmo que afirmar a existência de um mundo exterior. Mesmo que se afirme que os eventos só podem ser manipulados após um processo de abstração via faculdade da razão e por meio da linguagem, Adeodato afirma que há ao menos um objeto exterior ao sujeito cognoscente e às ideias.

Isto é feito de maneira axiomática: do mesmo modo que o matemático postula a existência de um conjunto (como é feito no sistema de Zermelo-Fraenkel e mesmo na Teoria dos Conjuntos Ingênua), Adeodato postula a existência dos eventos sem maiores justificações. A tentativa de responder ao desafio idealista/solipsista de que não há objetos externos à mente 


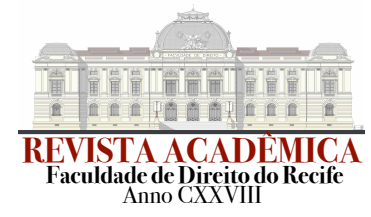

humana é substituído pela adoção de um duplo solipsismo à moda da filosofia retórica: o da espécie humana e o de cada sujeito dentre dela (ADEODATO, 2011, p. 36).

Assim, falta precisão quanto à posição de Adeodato sobre os eventos. Eles são percebidos como o mundo externo em um realismo indireto de raiz empirista ou de uma fenomenologia de matiz Husserliana? Apesar de Adeodato citar Husserl tanto no Ética \& Retórica quanto em seu Uma Teoria Retórica da Norma Jurídica e do Direito Subjetivo, não há propriamente uma discussão sobre intencionalidade da consciência ou de distinções entre indicação e significação. Isto faria toda diferença caso houvesse um desafio solipsista/ idealista quanto à existência de eventos ou não.

É importante ressaltar, aqui, que Wittgenstein não nega a existência de processos mentais, ou de operações altamente complexas ocorridas no sistema nervoso humano. (MARTINS, 2000, p. 33) (IF, §308). O que ele ressalta é que, ao filosofarmos, somos levados por uma certa intuição - a intuição fundamental das diversas teorias do cânone ocidental - a criar uma correspondência entre o signo e um estado mental, uma ideia. Não há propriamente uma espécie de behaviorismo.

\section{CONCLUSÃO}

Os argumentos aqui tecidos não tiveram, apesar de tudo, a teoria retórica como alvo direto. Não se pretendeu combater muitas das diversas facetas da obra de João Maurício Adeodato, que é extensa e tem apontamentos metodológicos seríssimos. Estamos de acordo, inclusive, com muitos dos posicionamentos do autor quanto a uma ética da tolerância, a rejeição dos jusnaturalismos, uma postura cética diante das verdades absolutas. $\mathrm{O}$ mesmo se dá em relação a algumas teses mais afastadas de uma base gnoseológica/epistemológica, como a de que o direito brasileiro é periférico e que se mostra ao mundo como fazendo parte de uma modernidade incompleta. 


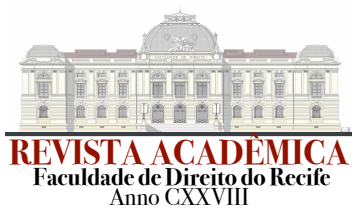

As ressalvas são apenas quanto aos fundamentos epistemológicos que forneceriam as vigas de sustentação para o soerguimento do edifício retórico. É que, para uma teoria que se pretende radicalmente contrária aos diversos ontologismos, racionalismos extremados e grandes teses metafísicas sobre o a priori, defendemos que rompimento deveria ser mais efetivo em relação à tradição. Há, então, uma certa resposta contrária à da tradição sem que, contudo, abandone-se muitos de seus pressupostos e preconceitos, do qual destacamos o de que a linguagem serve eminentemente para fazer representações e classificar ideias/estados mentais/conceitos empíricos.

A abordagem da linguagem feita por Wittgenstein, que dá destaque a vivências, técnicas, à interação humana e seus complexos parece ser extremamente adequada para figurar como um pano de fundo alternativo. A explicação do direito por meio de jogos de linguagem, uso, gramática das palavras e forma de vida abre caminhos vastos que podem nos levar além das grandes dicotomias tratadas repetidamente pela filosofia e pela teoria geral do direito.

\section{REFERÊNCIAS}

ADEODATO, João Maurício Leitão. Uma Teoria Retórica da Norma Jurídica e do Direito Subjetivo. São Paulo: Noeses, 2011.

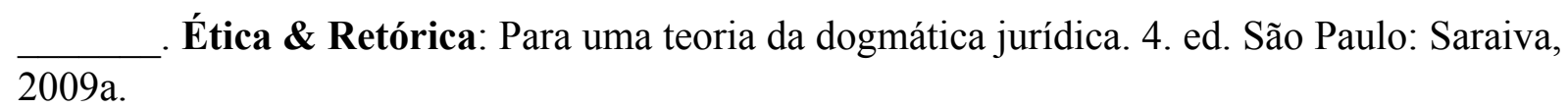
. A retórica constitucional (sobre tolerância, direitos humanos e outros fundamentos éticos do direito positivo). São Paulo: Saraiva, 2009 b.

. Filosofia do Direito: Uma crítica à verdade na ética e na ciência. 5. ed. São Paulo: Saraiva, 2013.

BIX, Brian. Law, Language, and Legal Determinacy. Oxford: Oxford Press, 1993.

CASTRO JR., Torquato da Silva . A Bola Do Jogo: uma metáfora performativa para o desafio da pragmática da norma jurídica. In: Adeodato, J. M.; Bittar, E. C. B.. (Org.). Filosofia e 


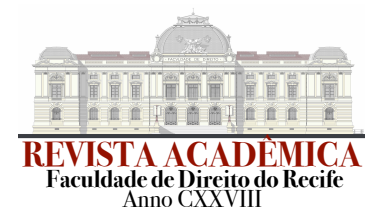

Teoria Geral do Direito: homenagem a Tercio Sampaio Ferraz Júnior. São Paulo: Quartier Latin, 2011, pp. 1075-1088.

DEETZ, Stanley. Words Without Things: Toward a Social Phenomenology of Language. Quarterly Journal of Speech. v. 59, pp. 40-51, 1973.

HART, H. L. A., The Concept of Law. Oxford: Oxford Press, 2012.

HEIDEGGER, Martin. Identity and difference. Tradução de Joan Stambaugh. Nova Iorque: Harper \& Row, 1969.

MARTINS, Helena. Sobre a estabilidade do significado em Wittgenstein. Veredas: Revista de estudos lingüísticos. v. 4, n. 2. Juiz de Fora: Editora da UFJF, 2000

STONE, Martin. Focalizando o direito: o que a interpretação jurídica não é. In: MARMOR, Andrei (ed.). Direito e interpretação: ensaios de filosofia do direito. Tradução de Luís Carlos Borges. São Paulo: Martins Fontes, 2000.

WITTGENSTEIN, Ludwig. Investigações Filosóficas. Trad. Marcos G. Montagnoli. Petrópolis: Vozes, 1994.

On Certainty. Edição bilíngue. Tradução de Denis Paul e G. E. M. Anscombe. Nova Iorque: HarperCollins, 1972.

Observações Filosóficas. Tradução de Adail Sobral e Maria Stela Gonçalves. São Paulo: Loyola, 2005.

Gramática Filosófica. Tradução de Luís Carlos Borges. São Paulo: Loyola, 2003.

- Tractatus Logico-Philosophicus. 4. ed. Edição bilíngue. Tradução de Luiz Henrique Borges dos Santos. São Paulo: Edusp, 2008.

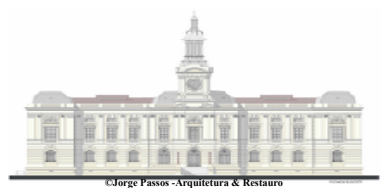

